Sprachwissenschaftler wird sich seinerseits aus diesen Beiträgen ein Bild darüber machen können, wo die ungelösten Probleme des Altgriechischen liegen. Man stößt in diesen inhaltlich zwar verschiedenen Beiträgen immer wieder auf zweierlei Fragestellungen: einerseits ein bemerkenswerter 'appositioneller' Satzbau des Altgriechischen, die manche auf den ersten Blick seltsame syntaktische Erscheinung mit sich bringt, andererseits pragmatisch stark differenzierte Funktionen der Satzkonstituenten. Jeder, der sich mit diesen Beiträgen auch nur oberflächlich vertraut gemacht hat, wird zusammen mit dem aktuellen Rezensenten hoffen, daß dieser Sammelband nicht der letzte seiner Reihe ist.

Matjaž Babič

\title{
GRAMÁTICA DESCRIPTIVA DE LA LENGUA ESPAÑOLA, dirigida por Ignacio Bosque y Violeta Demonte, publicada por la Real Academia Española, Colección Nebrija y Bello. Madrid: Espasa Calpe, 1999
}

La Gramática Descriptiva de la Lengua Española es una obra muy extensa de 5351 páginas más las páginas de introducción, relación de autores e índice de contenidos, publicada en tres volúmenes y dirigida por dos eminentes lingüistas españoles Ignacio Bosque Muñoz, Catedrático de Lengua Española en la Universidad Complutense de Madrid y miembro de la Real Academia Española, y Violeta Demonte Barreto, Catedrática de Lengua Española en la Universidad Autónoma de Madrid.

Los directores, además de ser autores de varios artículos de la obra, presentaron el proyecto de la elaboración de una gramática descriptiva del español en 1993 cuando el director de la Real Academia Española era Lázaro Carreter que decidió que la publicación de una obra de tal envergadura debería pasar por la RAE. Seis años más tarde, en octubre de 1999, el proyecto se concluye y Lázaro Carreter, entonces ya ex director de la RAE, se encarga de introducir la obra. El Instituto Universitario Ortega y Gasset acogió el proyecto desde el principio en su sede de Madrid y el Ministerio de Educación y Ciencia (luego de Educación y Cultura) se encargó de una parte importante de la financiación.

La Gramática Descriptiva de la Lengua Española es, según las palabras de los propios directores, la gramática más detallada que se haya escrito sobre el español $\mathrm{y}$, si se descuentan algunas gramáticas francesas clásicas, una de las obras más exhaustivas que se hayan publicado nunca para cualquier idioma. Tiene cuatro características fundamentales: es una obra colectiva, un estudio descriptivo del idioma, una obra de múltiple acceso y una obra que incorpora nuevos temas en la gramática del español.

Los autores de esta gramática son 73 renombrados lingüistas y gramáticos españoles y latinoamericanos. Los dos directores se encargaron de coordinar los textos de todos los autores y darles homogeneidad y cohesión. Aún siendo colectiva la 
gramática no es una recopilación de ensayos superpuestos o de monografías independientes. Los directores se han esforzado por lograr "un tono expositivo relativamente homogéneo, un vocabulario descriptivo común en los aspectos esenciales del análisis y un marco conceptual de conciliación que careciera de contradicciones" (pág. XX). No se trata tampoco de una gramática normativa sino de la descripción de la lengua tal como figura en el título de la gramática. Es una gramática de referencia, repleta de referencias cruzadas, es decir, una obra de consulta, de información destinada a los especialistas y a otros usuarios de la lengua (profesores, estudiantes, alumnos, comunicólogos, estudiantes extranjeros, etc). Se trata de un trabajo científico exhaustivo que combina las teorías tradicionales con las últimas tendencias en la lingüística. Es una obra de múltiple acceso que contiene cuatro índices que permiten al lector la mejor información posible sobre una cuestión determinada: el índice de los contenidos que se encuentra en el volumen 1 y los índices de materias con 5.400 entradas, de voces con 6.300 entradas y de obras citadas con 4.500 entradas que figuran en el volumen 3 (estos últimos obra de Ma. Victoria Pavón Lucero).

El contenido de la obra se estructura en 78 capítulos de diferente extensión cuyos límites decidieron los directores de la obra según la importancia objetiva o la complejidad del tema estudiado. Todos los artículos son homogéneos en la forma, están divididos en apartados de numeración corrida, presentan muchísimos ejemplos y llevan al final una copiosa lista de textos citados y de referencias bibliográficas. Los capítulos se agrupan a su vez en cinco partes temáticas.

La primera parte, Sintaxis básica de las clases de palabras, está formada por 23 capítulos (del 1 al 23) dedicados a la descripción pormenorizada de las clases de palabras y de los sintagmas que estas palabras constituyen. Se excluye el sintagma verbal que se estudia en los capítulos siguientes. Los capítulos se dedican al sustantivo, al adjetivo, al artículo, a los cuantificadores, a la estructura del sintagma nominal, a los pronombres personales, a las partículas.

En la segunda parte, Las construcciones sintácticas fundamentales, que consta de 19 capitulos (del 24 al 43), se analizan la transitividad y la intransitividad, las construcciones inacusativas y pasivas, las construcciones con se, el infinitivo, la negación, la elipsis, las clases de oraciones, su estructura y la constitución del sintagma verbal.

La tercera parte titulada Relaciones temporales, aspectuales y modales tiene 9 capítulos (del 44 al 53). Varios capítulos se dedican al problema del tiempo y del aspecto en los que aparecen diferentes posturas de los autores que se dedican a estos complejos temas (El tiempo verbal. Los tiempos simples. Los tiempos compuestos. El aspecto léxico. El tiempo verbal y la sintaxis oracional. La consecutio temporum. Los complementos adverbiales temporales). Los capítulos siguientes presentan temas como los modos (Modo y modalidad. El modo en las subordinadas relativas y adverbiales), las perífrasis verbales, el gerundio no perifrástico, los verbos auxiliares.

La cuarta parte, Entre la oración y el discurso, abarca los capítulos 54 a 78 y se dedica a examinar los tipos de oraciones en los que se manifiestan más explícitamente 
las inferencias de los hablantes, se valora la aportación informativa o se marca más fuertemente la modalidad. Los capítulos de esta parte presentan las relaciones paratácticas e hipotácticas, el discurso directo e indirecto, la subordinación adverbial, los actos de habla, las construcciones exclamativas, los enunciados interrogativos, los marcadores del discurso.

La última parte (del capítulo 66 al 78), Morfología, se dedica a la flexión y a la formación de palabras. Tras un capítulo de introducción, los siguientes analizan la relación de la morfología con la fonología y la sintaxis, la derivación nominal, adjetival, apreciativa y verbal, la composición, la flexión nominal y verbal y diversos procesos morfológicos.

La Gramática Descriptiva de la Lengua Española es, a pesar de su tamaño y su carácter de obra colectiva, una obra de manejo fácil y comprensible gracias también a su sistema de indicaciones. Los libros vienen acompañados de tres tablas iguales (una en cada volumen) que funcionan como guía del lector. El libro funciona como un hipertexto con múltiples subtextos. Se puede leer y consultar de diferentes maneras y direcciones lo que nos hace pensar en un juego de ordenador o en la $\mathrm{R} /$ rayuela. Los lectores pueden leer la obra linealmente o seguir una palabra, un sintagma a través de los textos gracias a los índices, flechas y números sembrados en los puntos estratégicos de la gramática.

Aunque se le podría criticar el hecho de que no incluye de manera suficiente las numerosas particularidades del español de América hay que reconocer que es la gramática del español más exhaustiva que se haya publicado hasta el presente y seguramente ocupará un lugar muy importante entre las obras dedicadas a la lengua española.

Jasmina Markič

\section{Pavle Merkù, SLOVENSKA KRAJEVNa IMENA V ITALIJI, Priročnik/ TOPONIMI SLOVENI IN ITALIA, Manuale, Mladika, Trst 1999; pp. 126.}

Anni addietro abbiamo potuto, sulle pagine di questa stessa rivista, attirare l'attenzione dei linguisti e in special modo dei cultori di toponomastica sull'apparizione di un'opera che trattava i toponimi sloveni, Slovenska krajevna imena/Les noms de lieux en Slovénie, Linguistica 28. Lamentavamo, in quell'occasione, che i ricercatori non avessero accolto anche i nomi di luoghi all'infuori dell'allora Repubblica Federale Slovena. Con il lavoro di Pavle Merkù che vede la luce a Trieste, questa mancanza è stata eliminata per la parte del territorio sloveno che si trova nella Repubblica Italiana, vale a dire, nella Regione autonoma del Friuli-Venezia Giulia. 